\title{
違法ドラッグの理化学検査の現状と課題
}

\author{
長谷川貴志, ${ }^{*}$ 高橋和長, 西條雅明, 吹譯友秀, 元木裕二
}

\section{Current Situation and Issues for Analyzing Illegal Drug Products}

\author{
Takashi Hasegawa, ${ }^{*}$ Kazunaga Takahashi, Masaaki Saijo, Tomohide Fukiwake, and Yuji Motoki \\ Chiba Prefectural Institute of Public Health; 666-2 Nitona-cho, Chuo-ku, Chiba 260-8715, Japan.
}

(Received August 17, 2012)

\begin{abstract}
Thirty-two psychotropic substances (31 compounds and one plant) have been controlled as designated substances (Shitei-yakubutsu) in Japan by the Pharmaceutical Affairs Law since April 2007. Although the trafficking of these drugs has decreased because of this regulation, new designer drugs (synthetic cannabinoids and cathinones) have appeared, one after the other. As of October 2011, 40 compounds had been newly added to this category. Analytical methods have become more complicated due to this increase in the number of designated substances. Moreover, many reference substances for such designated substances and other new designer drugs are not commercially available. For the reasons stated above, a lot of time and effort is required to analyze the illegal drug products available on the market.
\end{abstract}

Key words_ — designated substance; Shitei-yakubutsu; designer drug; drug abuse

\section{1.はじめに}

違法ドラッグは，法律上明確な定義はないが，麻 薬や覚せい剤に指定されておらず，それらと類似の 有害性が疑われる物質であって，人に乱用させるこ とを目的として販売されているものである. 近年, 合法ハーブ（脱法ハーブ）などとして販売されてい る違法ドラッグが広く乱用され，それらの製品によ ると思われる健康被害事例（死亡例も含む）が多発 し，社会問題となっている. 平成 19 年 4 月の改正 薬事法の施行により「中枢神経作用を有する蓋然性 が高く，保健衛生上の危害が発生するおそれのある 薬物や植物」として 31 物質 1 植物が指定薬物に指 定され，これらを含む製品の製造，輸入，販売等が 規制されることとなった．しかし，指定薬物に指定 されていない物質には規制が及ばないことから，既 存の指定薬物の構造を一部改変した指定薬物類似物 質や合成カンナビノイド類などの新規の違法ドラッ グ成分が次々検出されるようになつた. ${ }^{1-16)}$ このよ うな状況に対応するため, 指定薬物は次々と追加さ

The authors declare no conflict of interest.

千葉県衛生研究所（干260-8715 千葉市中央区仁戸名町 666-2)

${ }^{*}$ e-mail: t.hsgw20@pref.chiba.lg.jp

本総説は, 日本薬学会第 132 年会シンポジウム S09 で 発表したものを中心に記述したものである.
れ，麻薬に指定された 3 物質を除き，68物質 1 植 物（平成 23 年 10 月 20 日現在）が指定されている. しかし，依然として規制対象外である新規の違法ド ラッグ成分が検出されており「いたちごっこ」の状 況はあまり変わっていない.

\section{2. 理化学検査の現状と課題}

2-1. 千葉県における違法ドラッグ対策事業 千葉県では，県民への健康被害の未然防止及び流 通実態の把握を目的として, 平成 18 年度から違法 ドラッグ対策事業として年間 100 製品程度，違法ド ラッグ製品の試買検査を行っており，検査において 指定薬物が検出された場合，報道発表，関係自治体 への通報, 販売業者へ製品の販売中止及び自主回収 等の措置を行っている. 違法ドラッグの分析は「指 定薬物の分析法について (平成 19 年 5 月 21 日付薬 食監麻発第 0521002 号)」及び「指定薬物の測定結 果等について（平成 22 年 9 月 14 日付薬食監麻発 0914 第 5 号)」に準拠し検査を実施し，必要に応じ て TLCによる定性試験，標準添加法による確認試 験や HPLCによる定量試験等を実施している，指 定薬物制度が始まった平成 19 年度当初は, 指定薬 物の数が比較的少なく，ヘッドスペース $\mathrm{GC} / \mathrm{MS}$, GC/MS（1 条件）及び LC/MS（1 条件）によるス クリーニング分析を実施していたが，指定薬物の増 
加及び合成カンナビノイド類に対応するため，平成 22 年には GC/MS 及び LC/MS の分析条件が追加 され，現在ではへッドスペース GC/MS, GC/MS （2 条件）及び LC/MS（2 条件）でのスクリーニン グ分析を実施しており，検査に要する時間が増加し ている.

2-2. 標準品検査に用いる標準品は，指定薬 物に指定されている物質でも市販されていない物質 がある。また，指定薬物以外の新規の違法ドラッグ 成分の標準品も市販されていない物質が多い。さら に，新たに違法ドラッグとして流行すると予測され る物質は数多くあり，それらの標準品をあらかじめ
すべて揃えて検査することは困難である，標準品の 入手が違法ドラッグの検査を実施していく上での課 題の 1 つである。

2-3. 分析事例 Figure 1 に平成 22 年度の検体 の GC/MS（合成カンナビノイド類を対象とした測 定条件）の全イオンクロマトグラム及び検出された ピークにおけるマススペクトルを示した。 各ピーク について GC/MS のライブラリ検索を実施したと ころ，分析当時標準品を保有し $\mathrm{GC} / \mathrm{MS}$ のマスス ペクトルをライブラリに登録していたため, Compound 2 は JWH-015 と, Compound 3 は AM694 と推定することができた。 また，LC/MS の分析結 (a)

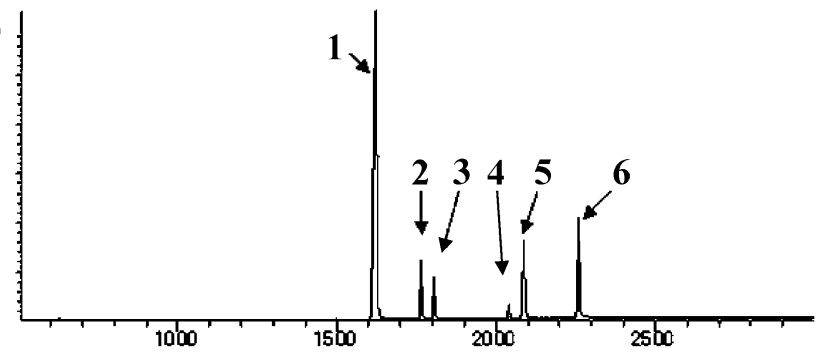

(b)

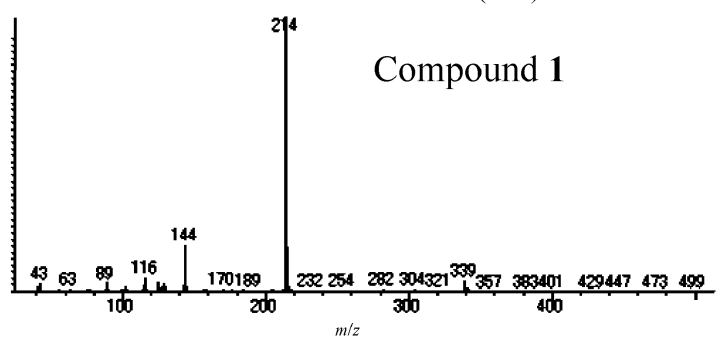

(e)

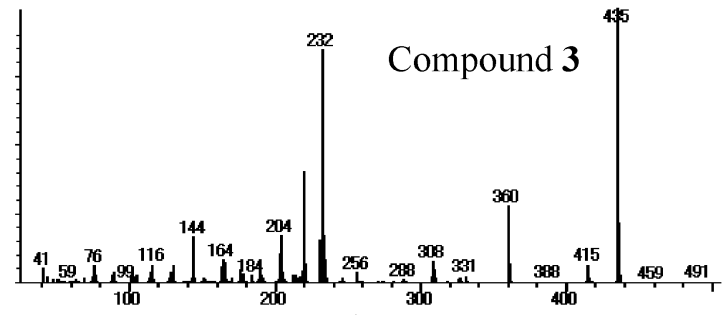

(g)

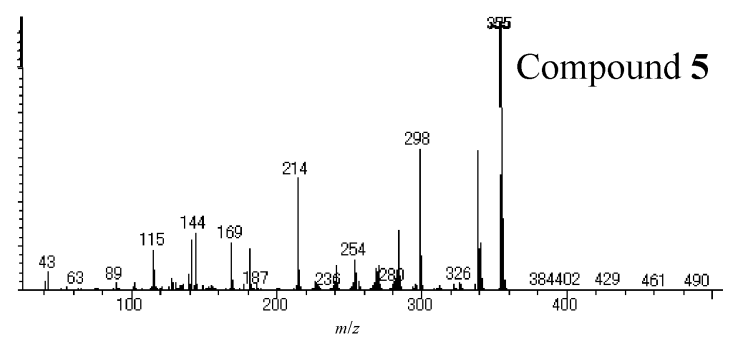

(c)

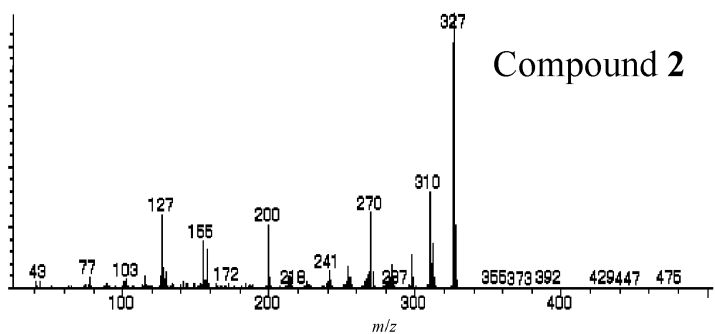

(f)

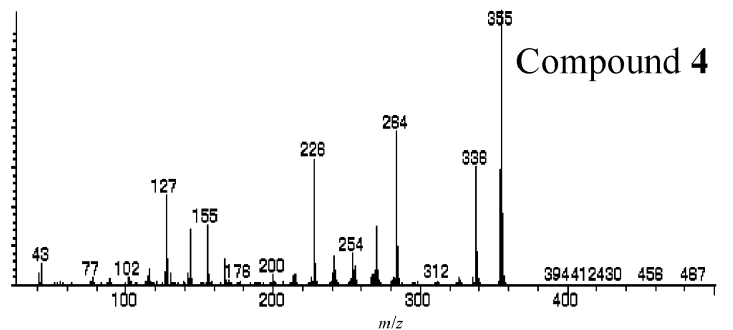

(h)

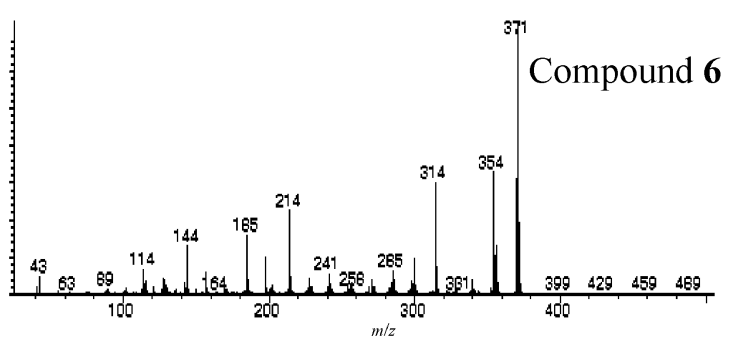

Fig. 1. Total Ion Current (TIC) Chromatogram of GC/MS Analysis (a) and the Mass Spectra of the Detected Peaks at the Retention Times $16.2(\mathrm{~b}, \mathbf{1}), 17.7(\mathrm{c}, \mathbf{2}), 18.1(\mathrm{~d}, \mathbf{3}), 20.4(\mathrm{e}, \mathbf{4}), 20.9(\mathrm{f}, \mathbf{5})$, and $22.6(\mathrm{~g}, \mathbf{6})$ of a Sample Solution

GC/MS conditions: ionization, electron-impact ionization; column, HP-1MS ( $30 \mathrm{~m} \times 0.25 \mathrm{~mm}$ i.d., $0.25 \mu \mathrm{m}$, Agilent); carrier gas, helium; flow rate, $1.1 \mathrm{~mL} /$ min; injector temperature, $200^{\circ} \mathrm{C}$; oven temperature program, $200^{\circ} \mathrm{C}(1 \mathrm{~min}$ hold $)-5^{\circ} \mathrm{C} / \mathrm{min}-310^{\circ} \mathrm{C}(7 \mathrm{~min}$ hold $)$; electron energy, 70 eV; scan range, $m / z 40-600$; injection volume, $1 \mu \mathrm{L}$. 
果から，保持時間及びマススペクトルが標準品と一 致したことから，ぞれぞれ同定することができた.

Compound 1 は GC/MS のライブラリ検索からは JWH-250 と一致率が高かつたが，Compound 1 の 分子イオンピーク $\left[\mathbf{M}^{+}\right]$は $m / z 339$ であり, JWH-250 の分子イオンピーク $\left[\mathbf{M}^{+}\right](m / z 335)$

(a)

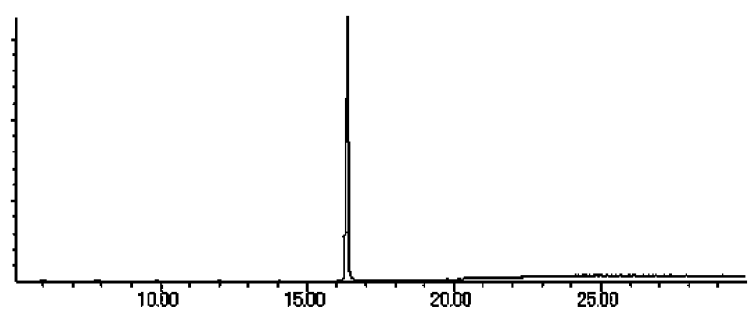

とは異なっていた [Figs. 1(b) and 2(b)]。また， $\mathrm{LC} / \mathrm{MS}$ 分析の結果, $m / z 340$ に $[\mathrm{M}+\mathrm{H}]+$ イオン のピークが観察された $[$ Fig. 3(c) ]. 以上の結果及 び国内外の新規違法ドラッグ成分の検出状況17) か Compound 1 は JWH-203 と推定された（Fig. 4). Compound 4, 5 及び 6 は GC/MS のライブラリ検 (b)

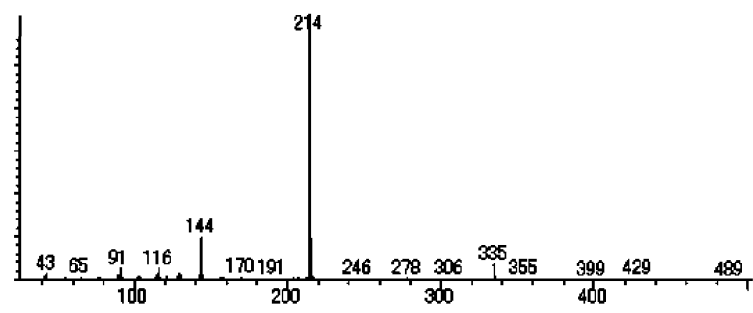

$m / z$

Fig. 2. TIC Chromatogram of GC/MS Analysis (a) and the Mass Spectrum (b) of Standard Solution of JWH-251 (100 $\mu \mathrm{g} / \mathrm{mL}$ in Methanol)

GC/MS conditions were same as in Fig. 1.

(a)

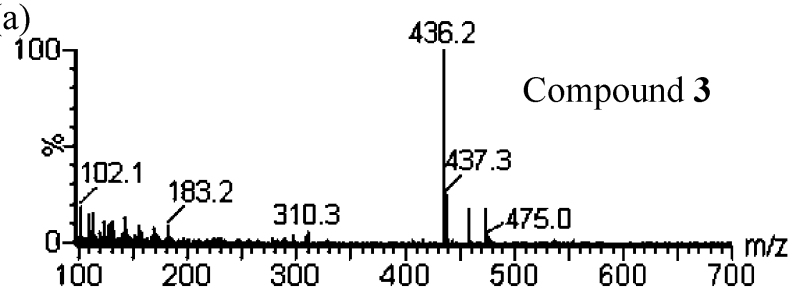

(c)

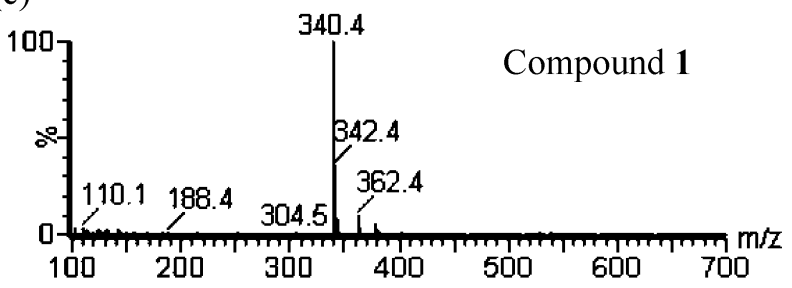

(e)

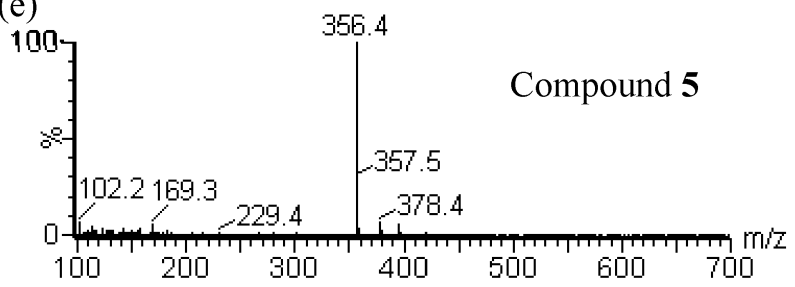

(b)

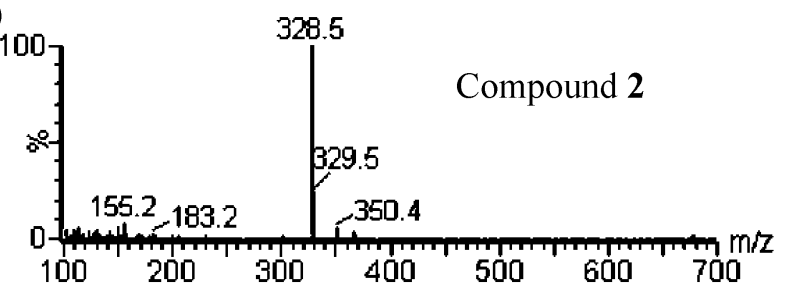

(d)

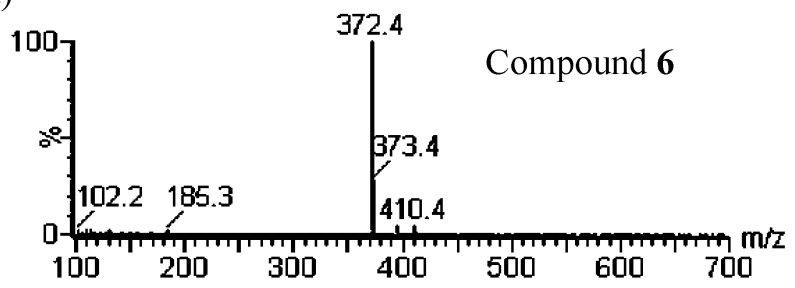

(f)

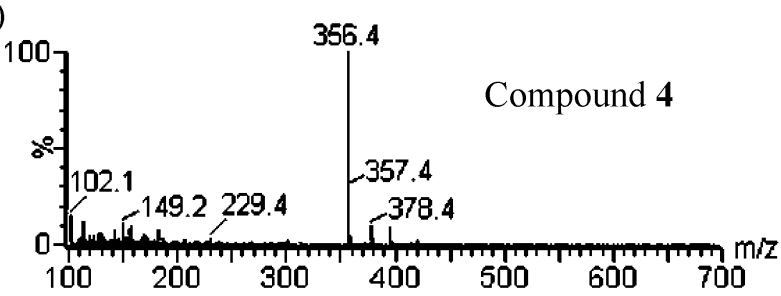

Fig. 3. LC/MS Spectra of the Detected Peaks at $11.8(\mathrm{a}, \mathbf{3}), 15.2(\mathrm{~b}, 2), 18.8(\mathrm{c}, \mathbf{1}), 20.1(\mathrm{~d}, \mathbf{6}), 22.2(\mathrm{e}, \mathbf{5})$, and $22.7(\mathrm{f}, \mathbf{4})$ of a Sample Solution

LC/MS conditions: column, XBridge C18 (150 mm $\times 2.1 \mathrm{~mm}$ i.d., $3.5 \mu \mathrm{m}$, Waters $)$; mobile phase A, $0.1 \%$ formic acid aqueous solution; mobile phase B, acetonitrile/methanol $(3: 2)$ containing $0.1 \%$ formic acid; gradient program, $50 \%$ B ( 0 min) $-90 \%$ B ( $30-35$ min); ionization, electorospray ionization; mode, positive; capillary voltage, $3.0 \mathrm{kV}$; desolvation gas flow, $\mathrm{N}_{2} 800 \mathrm{~L} / \mathrm{h}$; desolvation temperature, $350^{\circ} \mathrm{C}$; cone voltage, $30 \mathrm{~V}$; scan range, $m / z$ 100-700; injection volume, $1 \mu \mathrm{L}$. 
索で一致する物質はなく，分子イオンピーク $\left[\mathrm{M}^{+}\right]$ は，それぞれ $m / z 335$ (Compound 4),$m / z 335$ (Compound 5) 及び $m / z 371$ (Compound 6) であ つた [Figs. 1(f)-(h)]。また, LC/MS 分析の結 果， $[\mathrm{M}+\mathrm{H}]+$ イオンが，それぞれ $m / z 356$ (Compound 4),$m / z 356$ (Compound 5) 及び $m / z 372$ （Compound 6）に観測された [Figs. 3(d)-(f)]. 以上の結果，国内外の新規違法ドラッグ成分の検出 状況及び論文 ${ }^{11,13)}$ 検索の結果から, Compound 4 は JWH-019, Compound 5 は JWH-122, Compound 6 はJWH-081 と推定された。JWH-203, JWH-019, JWH-122 及び JWH-081 は Cayman Chemical Company より標準品が販売されていたため，それらを 購入し，それぞれ同定することができた。なお，

Fig. 1 に示した製品から検出されたいずれの物質も 当該製品購入時は指定薬物には指定されていなかつ
たが，現在では指定薬物に指定されている.

2-4. 違法ドラッグ検査結果＼cjkstart平成 19 年度か ら平成 22 年度までの千葉県における検査結果を Table 1 に示した。指定薬物は平成 19 年 4 月に 31 物質 1 植物が指定され，その後次々と追加されてき たが，指定薬物が検出された製品は，平成 21 年度 bk-MBDB が検出された 2 製品のみであり非常に少 なかった。一方，指定薬物以外の違法ドラッグ成分 が検出された製品は，平成 19-20 年度は少なく，指 定薬物制度による規制強化の効果が認められたもの の, 平成 21 年度は 39 製品, 平成 22 年度は 65 製 品と急増した．検出された違法ドラッグ成分は JWH018 や JWH-250 等の合成カンナビノイド類や 4-メ チルメトカチノンや 4-メトキシメトカチノン等の 合成力チノン類であった。このように規制対象外で ある新規違法ドラッグ成分が多くの製品から検出さ<smiles>CCCCCn1cc(C(=O)Cc2ccccc2Cl)c2ccccc21</smiles>

JWH-203 (Compound 1)

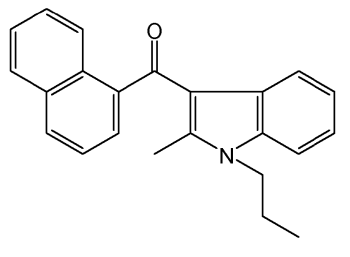

JWH-015 (Compound 2)

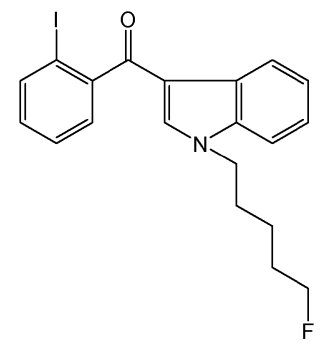

AM694 (Compound 3)

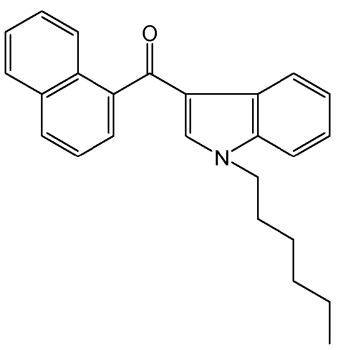

JWH-019 (Compound 4)

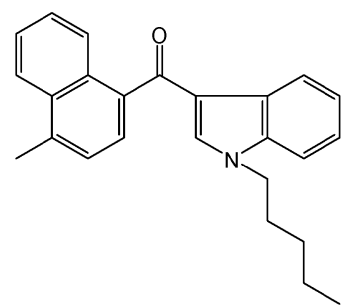

JWH-122 (Compound 5)

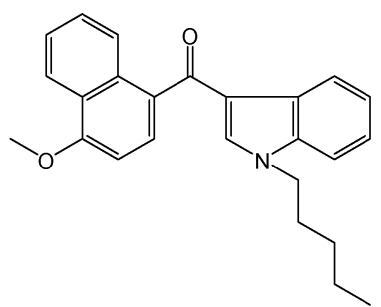

JWH-081(Compound 6)

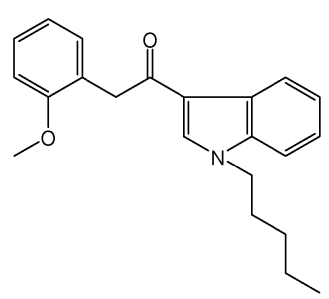

JWH-250

Fig. 4. Structures of Synthetic Cannabinoids

Table 1. Inspection Results of Illigal Drug Products

\begin{tabular}{cccc}
\hline \hline Year. Month & $\begin{array}{c}\text { Total Number of } \\
\text { Samples }\end{array}$ & $\begin{array}{c}\text { Number of Samples of Detected Designated } \\
\text { Substances }\end{array}$ & $\begin{array}{c}\text { Number of Samples of Detected Designer } \\
\text { Drugs Except Designated Substances }\end{array}$ \\
\hline $2007.4-2008.3$ & 114 & 0 & 2 \\
$2008.4-2009.3$ & 100 & 0 & 0 \\
$2009.4-2010.3$ & 84 & 2 & 39 \\
$2010.4-2011.3$ & 100 & 0 & 65 \\
\hline
\end{tabular}


れており，違法ドラッグの検査においては新規成分 に対応することが重要となっている．これら指定薬 物以外の新規違法ドラッグ成分の検出状況は千葉県 薬務課を通じて厚生労働省に提供しており，違法ド ラッグ成分を指定薬物に指定する際の一助となって いると思われる。

2-5. 新規違法ドラッグ成分の対応 新規違法 ドラッグ成分の分析は，標準品が入手可能な場合は それらの標準品を用いて分析するが，標準品が入手 できない場合は単離・精製し，NMR 等を用いての 構造解析が必要である。千葉県衛生研究所では NMR や高分解能質量分析計を保有していないた め, 国立医薬品食品衛生研究所生薬部と共同で構造 解析を行っている。しかし，単離・精製には時間を 要することから, 迅速な対応が難しいのが現状であ る.

\section{3. おわりに}

GC/MS や LC/MS 分析において, 標準品は非常 に重要である．指定薬物に指定されている物質の標 準品をあらかじめすべて揃えることが難しいことか ら，標準品の入手が違法ドラッグの検査を実施する 際の大きな課題となっている．また，指定薬物以外 の新規違法ドラッグ成分が次々と検出されているこ とから，日頃からの情報収集や違法ドラッグとして 流行すると予想される成分の標準品をあらかじめ入 手しておくことなど，新規成分に対して迅速に対応 できるよう準備しておくことが必要と思われる。

\section{REFERENCES}

1) Uchiyama N., Kikura-Hanajiri R., Kawahara N., Haishima Y., Goda Y., Chem. Pharm. Bull., 57, 439-441 (2009) .

2) Uchiyama N., Kikura-Hanajiri R., Kawahara N., Goda Y., Forensic Toxicol., 27, 61-66 (2009) .

3) Nagashima T., Takahashi M., Suzuki J., Seto T., Mori K., Ogino S., Ann. Rep. Tokyo Metr. Inst. P. H., 60, 81-84 (2009).

4) Takahashi K., Hasegawa T., Saijo M., Nagata T., Kikura-Hanajiri R., Goda Y., Annual
Report of the Chiba Prefectural Institute of Public Health, 58, 51-54 (2009)

5) Uchiyama N., Miyazawa N., Kawamura M., Kikura-Hanajiri R., Goda Y., Yakugaku Zasshi, 130, 263-270 (2010).

6) Uchiyama N., Kikura-Hanajiri R., Ogata J., Goda Y., Forensic Sci. Int., 198, 31-38 (2010).

7) Kikura-Hanajiri R., Kawamura M., Miyajima A., Sunouchi M., Goda Y., Forensic Sci. Int ., 198, 62-69 (2010) .

8) Suzuki J., Moriyasu T., Nagashima T., Kanai C., Shimizu M., Hamano T., Nagayama T., Ann. Rep. Tokyo Metr. Inst. P. H., 61, 163172 (2010).

9) Kikura-Hanajiri R., Uchiyama N., Goda Y., Leg. Med., 13, 109-115 (2011).

10) Uchiyama N., Kikura-Hanajiri R., Goda Y., Chem. Pharm. Bull., 59, 1203-1205 (2011).

11) Uchiyama N., Kawamura M., Kikura-Hanajiri R., Goda Y., Forensic Toxicol., 29, 25-37 (2011).

12) Nakajima J., Takahashi M., Seto T., Suzuki J., Forensic Toxicol., 29, 51-55 (2011).

13) Nakajima J., Takahashi M., Seto T., Kanai C., Suzuki J., Yoshida M., Hamano T., Forensic Toxicol., 29, 95-110 (2011).

14） Nakajima J., Takahashi M., Nakano R., Seto T., Suzuki J., Yoshida M., Kanai C., Hamano T., Forensic Toxicol., 29, 132-141 (2011).

15) Nagashima T., Suzuki J., Moriyasu T., Yoshida M., Shimizu M., Hamano T., Nakae D., Ann. Rep. Tokyo Metr. Inst. P. H., 62, 99105 (2011).

16) Nakajima J., Takahashi M., Seto T., Yoshida M., Kanai C., Suzuki J., Hamano T., Forensic Toxicol., 30, 33-44 (2012).

17) European Monitoring Centre for Drugs and Drug Addition (EMCDDA)-Europol 2010 Annual Report on the implementation of Council Decision 2005/387/JHA: 〈http://www. emcdda.europa.eu/attachements.cfm/att_132 857_EN_EMCDDA-Europol\%20Annual\% 20 Report\%202010A.pdf $\rangle$, cited 1 August, 2012. 